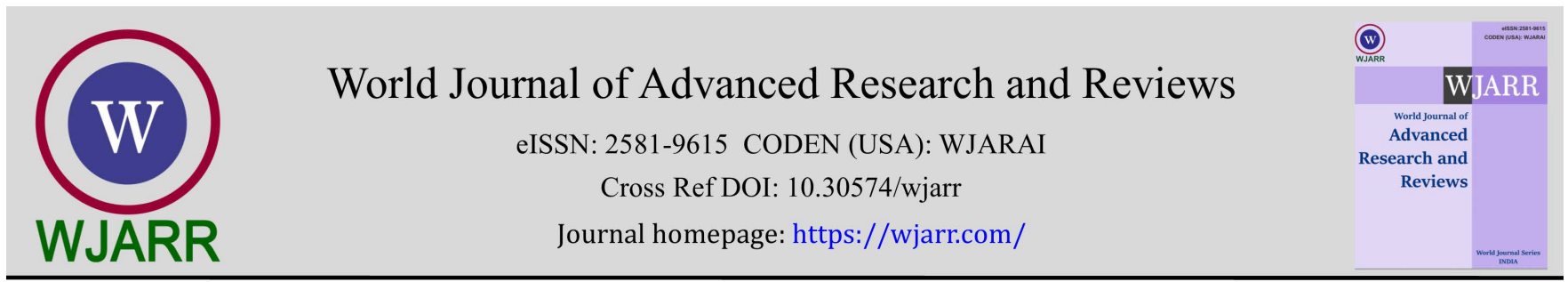

(REVIEW ARTICLE)

Check for updates

\title{
Review on Pharmacognosy, phytochemistry and pharmacological activity of Taraxacum officinale (Dandelion plant)
}

\author{
Prajakta N. Dongare *, Tejashri B. Kadu, Ashish L. Pohane, Sachin J. Dighade and Priyadarshani G. Patil \\ VYWS'S Institute of Pharmacy and Research, Badnera, Amravati. 444701 Maharashtra, India.
}

World Journal of Advanced Research and Reviews, 2021, 12(02), 212-218

Publication history: Received on 30 September 2021; revised on 06 November 2021; accepted on 08 November 2021

Article DOI: https://doi.org/10.30574/wjarr.2021.12.2.0570

\begin{abstract}
Taraxacum officinale (dandelion), a member of the Asteraceae family, commonly found in the temperate zone of the Northern hemisphere, is the perennial herb, forming a rosette leaf, golden yellow flowers that bloom year round. Dandelion leaves, roots and flowers is used in many traditional and modern herbal medicinal systems. On phytochemical investigation, Dandelion herb contains one or more vital phytochemical constituents. Similarly Among the most important compounds in dandelion Contains sesquiterpene lactones which is a bitter element, principally contains taraxacin and taraxacerin, which is principally important in mechanism of liver functions related with hepatoprotective action. Besides that result of the phytochemical investigation revealed the presence of sterols, phenolic acids, flavonoids, that have been shown to be associated with numerous pharmacological effects such as Antioxidants, anti immflammatory, antidiabetics, antitumor activity. Along with that the Dandelion leaves are a high efficient source of vitamins and minerals, including beta carotene, non-provitamin A carotenoids, xanthophylls, chlorophyll, vitamins C and D, many of the B-complex vitamins, choline, iron, silicon, magnesium, sodium, potassium, zinc, manganese, copper, and phosphorous which is also useful as a several nutritive action. This review will point out areas for future research of phytochemicals containing Taraxacum officinale where they shows more effective against various ailments and shows recent effective pharmacological activity
\end{abstract}

Keywords: Taraxacum officinale; Sesquiterpene lactone; Hepatoprotective; Anticancer; Antioxidant; Antiinflammatory.

\section{Introduction}

Herbalists today believe that herbs can aid in the treatment of many ailments, serious as well as chronic disorders. Plant of genus Taraxacum officinale known as dandelion have long been used in traditional medicine. Taraxacum officinale is a herbaceous perennial belonging to family Asteraceae (Compositae). Dandelion is also known as pu gong ying in traditional Chinese medicine and simhadanti in Ayurvedic medicine. Its English folk name "piss-a-bed" and French nickname "pissenlit" both refer to the root's strong diuretic effect. This herb usually has deeply toothed hairless leaves, $5-30 \mathrm{~cm}$ long and $1-10 \mathrm{~cm}$ wide. It grows $3-35 \mathrm{~cm}$ in height, forming a rosette of leaves at ground level. It has single, golden yellow flowers on straight leafless hollow stems, which emerge from the centre of the rosette. Each flower consists of a collection of florets. Dandelion plants have tap roots, tapering from 2 to $3 \mathrm{~cm}$ wide and at least $15 \mathrm{~cm}$ in length. Roots are fleshy and brittle, and area dark brown color on the outside and white on the inside. Dandelion (Taraxacum officinale) possesses many health benefits as it is anti-hyperglycemic, anti-inflammatory, anti-diabetic, antimicrobial, hypolipedemic, immunostimulatory and anti-oxidative [1].

\footnotetext{
* Corresponding author: Prajakta N Dongare

Institute of Pharmacy and Research, Badnera, Amravati. 444701 Maharashtra, India.

Copyright $(2021$ Author(s) retain the copyright of this article. This article is published under the terms of the Creative Commons Attribution Liscense 4.0.
} 


\subsection{Plant Taxonomy}

Table 1 Taxanomy of plant Taraxacum officinale

\begin{tabular}{|l|l|}
\hline Scientific Classification & Name \\
\hline Botanical Name & Taraxacum officinale \\
\hline Kingdom & Plantae \\
\hline Phylum & Tracheophytes \\
\hline Class & Angiosperms \\
\hline Subclass & Eudicots \\
\hline order & Asterales \\
\hline family & Asteraceae \\
\hline Genus & Taraxacum \\
\hline
\end{tabular}

The genus is taxonomically complex, with some botanists dividing the group into about 34 macrospecies, and about 2000 microspecies, about 235 apomictic and polyploidy microspecies have been recorded in Great Britain and Ireland. Some botanists take a much narrower view andonly accept a total of about 60 species [2, 3].

\subsubsection{Selected species}

- Taraxacum albidum, a white-flowering Japanese dandelion

- Taraxacuma phrogenes, Paphos dandelion

- Taraxacum californicum, the endangered California dandelion

- Taraxacum centrasiaticum, the Xinjiang dandelion

- $\quad$ Taraxacum ceratophorum, northern dandelion 4

- Taraxacum farinosum, Turkish dandelion

- Taraxacum holmboei, Troödos dandelion

- Taraxacum japonicum, Japanese dandelion, no ring of smallish, downward-turned leaves under the flower head Seed dispersal Similar plants Classification Selected species T. albidum T. californicum T. japonicum T. laevigatum T. officinale T. platycarpum A Taraxacum officinale seed head with only one seed still attached Dandelion in Iran

- Taraxacum kok-saghyz, Russian dandelion, which produces rubber

- Taraxacum laevigatum, red-seeded dandelion, achenes reddish brown and leaves deeply cut throughout length, inner bracts' tips are hooded

- Taraxacum mirabile

- $\quad$ Taraxacum officinale (syn. T. officinale subsp. vulgare), common dandelion. Found in many forms.

- Taraxacum pankhurstianum

- $\quad$ Taraxacum platycarpum, the Korean dandelion.

\subsection{Morphological Description}

The species of Taraxacum are tap-rooted, perennial, herbaceous plants, native to temperate areas of the Northern Hemisphere. In general, the leaves are 5-25 cm (2" to 10") long or longer, simple, lobed, and form a basal rosette above the central taproot. Their shape can be oblanceolate, obovate, but more often rucinnate or pinnatisect with a winged petiole. Margin can vary in the deepness of the lobes, from lobeless to triangular dentate edges. The long taproot is dark greyish externally and white internally. It can be deep as $2 \mathrm{~m}$ and $2 \mathrm{~cm}$ wide. The flower heads are yellow to orange coloured, and are open in the daytime, but closed at night. The heads are borne singly on a hollow stem (scape) that is usually leafless and rises 1-10 cm (1/2" to 4") or more [3] above the leaves. Stems and leaves exude a white, milky latex when broken. A rosette may produce several flowering stems at a time. The flower heads are 2-5 cm (1" to 2") in diameter and consist entirely of ray florets. Contents Description these are individual pollen grains of the dandelion Taraxacum officinale. Segment of pappus fiber showing barbs. The pappus of a dandelion seed, which aids in wind- 
driven dispersal Field with flowering dandelions, Tatarstan, Russia Hawksbeard flower heads and ripe seeds are sometimes confused with dandelions. The flower heads mature into spherical seed heads sometimes called blowballs[4] containing many single-seeded fruits called achenes. Each achene is attached to a pappus of fine hair-like material which enables wind-aided dispersal over long distances. The flower head is surrounded by bracts (sometimes mistakenly called sepals) in two series. The inner bracts are erect until the seeds mature, then flex downward to allow the seeds to disperse. The outer bracts are often reflexed downward, but remain appressed in plants of the sections Palustria and Spectabilia. Some species drop the "parachute" from the achenes; the hair-like parachutes are called pappus, and they are modified sepals. Between the pappus and the achene is a stalk called a beak, which elongates as the fruit matures? The beak breaks off from the achene quite easily, separating the seed from the parachute.

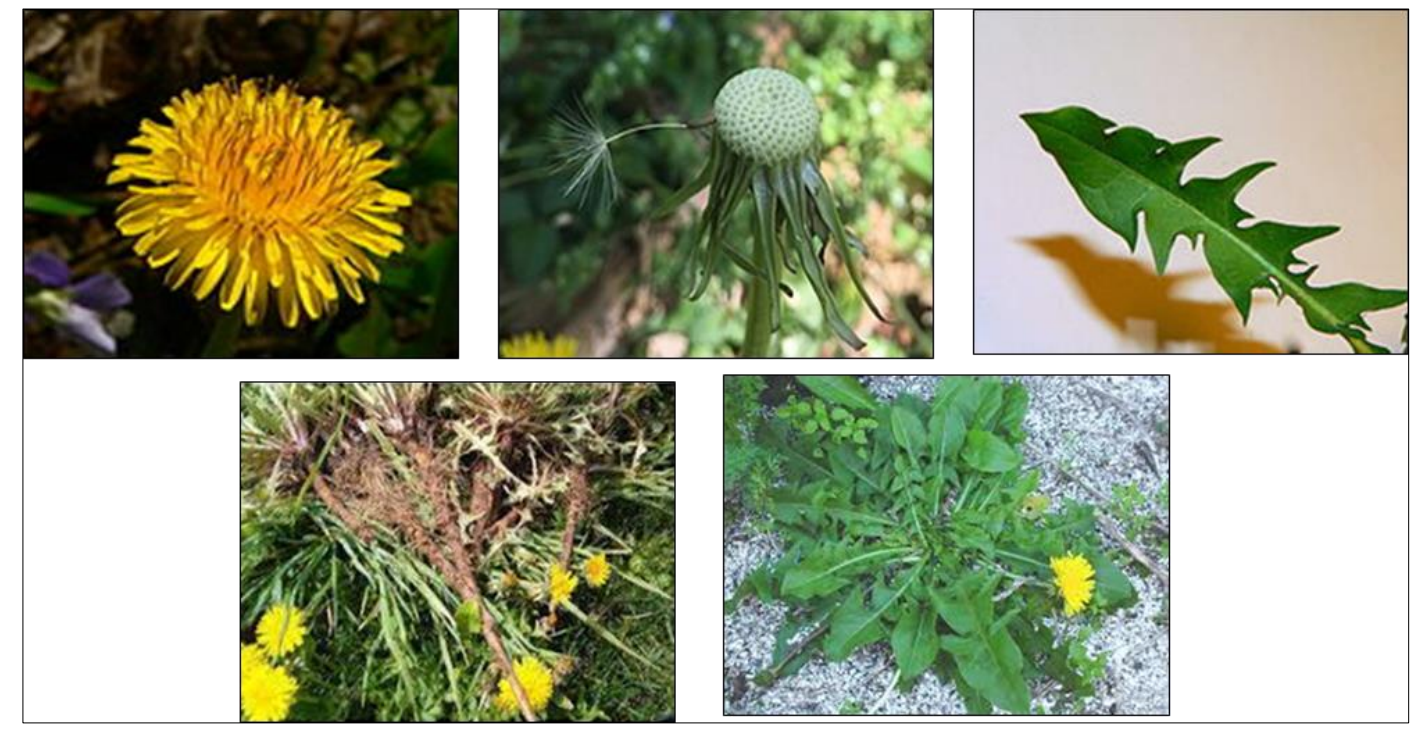

Figure 1 Taraxacum officinale plant morphological structure

\section{Phytochemistry}

The every herb contains one or more vital phytochemical Constitutents. Similarily Among the most important compounds in dandelion Conatins sesquiterpene lactones also which is ofenly known as bitter element, principally contains taraxacin and taraxacerin [5]. Dandelion leaves are a high efficient source of vitamins and minerals, including beta carotene, non-provitamin A carotenoids, xanthophylls, chlorophyll, vitamins C and D, many of the B-complex vitamins, choline, iron, silicon, magnesium, sodium, potassium, zinc, manganese, copper, and phosphorous[6].

\subsection{Sesquiterpene lactones}

The plant is rich source of sesquiterpene lactones or bitter principles Taraxacin or taraxinic acid or lactucopicrin [7], lactucin[8] and cichorin[9] are chief bitter principles and belong to the guaianolide class[10,11,12]. Taraxacin in concentrated solutions, forms precipitates with a number of alkaloidal reagents [13]. The plant contains a crystalline substance, taraxacerine or taraxaceron, which is reported to be bitter resin [11]. Taraxacoside, a type of acylated gamma-butyrolactone glycoside has been reported from the plant [14].

\subsection{Sterols}

Dandelion plant contains some sterols consisting Taraxasterol[15], $\psi$-taraxasterol, homotaraxasterol, $\beta$-sitosterol [16], stigmatsterol [17], campesterol [18].

\subsection{Flavonoids}

Some flavonoids such as Apigenin-7-glucoside, luteolin-7-glucoside, isorhamnetin 3-glucoside, luteolin-7-diglucoside, quercetin-7-glucoside, quercetin, luteolin, rutinand chrysoeriol. Phenolic acids: Caffeic acid, chlorogenic acid, chicoricacid also contains in Dandelion. 


\subsection{Triterpenes}

Dandelion root extract contains $\alpha$-amyrin, $\beta$-amyrin, lupeol, taraxol, taraxaserol, and cycloartenol. $3 \beta$-hydroxylup18(19)-ene-21-one has been reported from fresh roots of the plant [19]. Arnidiol and faradiol have been reported in research [20].

\subsection{Other constituents}

Some carotenoids such as Lutein and violaxanthin. Coumarins: Esculin and scopoletin. Lettucenin A, a serine proteinase: taraxalisin, amino acids, choline, mucilage and pectin.

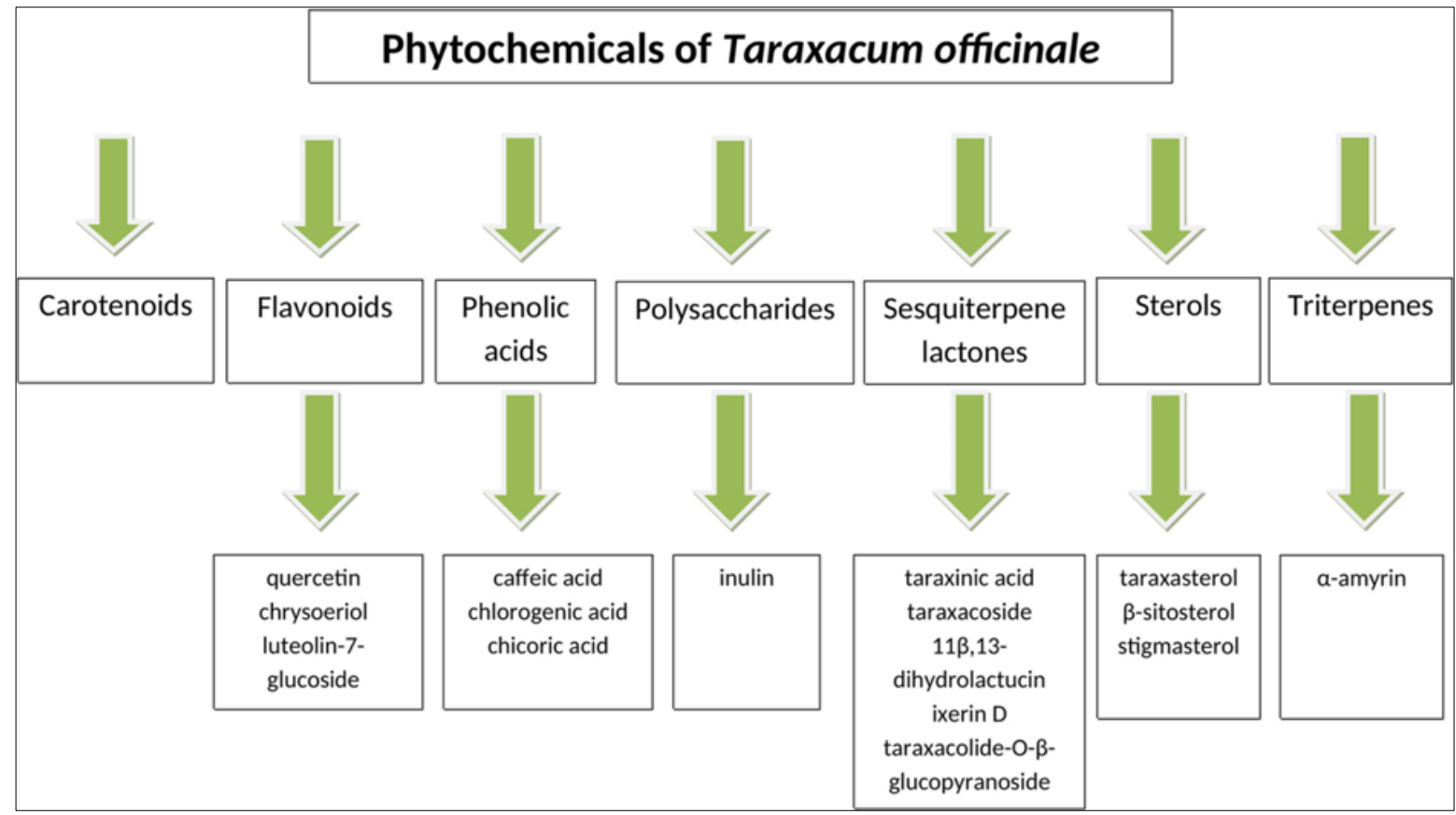

Figure 2 Phytochemicals containing in the plant taraxacumofficinale

\section{Pharmacology}

Taraxacum officinale plant have been reported as it contains bitter principle. These bitter principle helps in production of bile and bile flow from the liver. Hence these bitter compounds in the leave and root extracts helps to stimulate digestion and are mild laxative. Principally extract was used as hepatoprotective. Along with that the extracts of T. officinale have demonstrated antitumor, hypoglycemic, antifibrotic, antioxidant activity and anti-inflammatory activities.

\subsection{Hepatoprotective activity}

Taraxacum officinale has been used to cure liver and gallbladder disorders, which is attributed to its content of terpenoid and bitter sterol components such as taraxacin and taraxacerin [21].Current animal studies exhibited the efficacy of dandelion against the cytotoxic effects of CCL4, ethanol and sodium dichromate by improvement of liver and antioxidant enzymes. Improvement in liver function is associated with restoring histopathology of the liver cells. Polysacharides (Top1, Top2), flavonoids, phenolic, tannins, ascorbic acids, taraxol, taraerol, laevulin, inulin and luteolin are chemical compounds that are responsible for hepatoprotective effects of dandelion. Different mechanisms may be responsible for hepatoprotective effects of dandelion. Oligofructans as prebiotic compounds of dandelion induce the growth of intestinal probiotics and inhibit the release of LPS and FIAF and lipid accumulation in the body. Dandelion has anti-obesity effects via inhibition of digestive enzymes, lipid metabolism and adipogenesis. The lipogenesis effects of dandelion are associated with reduction of inflammation in the body and liver and improvement of insulin resistance and anti-oxidant condition. Although different documents confirmed the hepatoprotective effects of dandelion, preparing standard extracts of dandelion with high contents of effective compounds and designing large clinical studies. 


\subsection{Antifibrotic Effects}

Hepatic fibrosis is common sequel following chronic liver injury and reversal of fibrosis prior it attains the cirrhotic stage would be a clear therapeutic strategy. Taraxacum officinale extract has been evaluated against the drug and chemical induced hepatic fibrosis in experimental animals and came out with promising results. The study suggested that administration of Taraxacum officinale promote the complete regression of fibrosis and the enchantment of hepatic regenerative capabilities.

\subsection{Anticancer Activity}

Hepatocellular carcinoma (HCC) is one of the most common malignancies, which accounts for $90 \%$ of primary liver cancer [22]. In a very recent study it was found that relevant cytotoxic effect in T. lacistrum extract over HeLa and HepG2 cell lines [23]. Recent results pointed out that natural products, in particular those present in Taraxacum root extract, have great potential as non-toxic and effective alternatives to conventional modes of chemotherapy available today. Dandelion has been said to induce cytotoxicity in Hep G2 cells and decreases its viability below 40\% [24]. Taraxacum officinale extract significantly induced the secretion of TNF- $\alpha$ and IL-1 $\alpha$ and apoptosis of Hep G2 cells [25]. These strategies are clearly implicated in anticancer efficacy of dandelion.

\subsection{Antidiabetic activity}

Dandelion have demonstrated a series of antidiabetic effects, which are due to the pharmacological actions of compon ents such as sesquiterpene lactones, triterpenes/phytosterols (taraxasterol), phenols, flavonoids, and phenolic acids[25]. Therefore, a possible explanation for the effects and mechanisms of dandelion on Type 2 Diabetes could be its interaction with factors involved in the metabolic syndrome (lipid metabolism, glucose metabolism, protein metabolism, $\alpha$ - and $\beta$-cells dysfunction [26]. The mechanisms by which plant-derived compounds manifest their antidiabetic properties are [27]

- Inhibition of renal glucose reabsorption.

- $\quad$ Reduction of the activity of carbohydrate enzymes ( $\alpha$ amylase with $\beta$-galactosidase and $\alpha$-glucosidase).

- Reduction of dietary blood sugar (which stimulates hepatic glycolysis and glycogenesis).

- Inhibition of potassium channel flow.

\subsection{Anti-inflammatory Activity}

Dandelion leaf extract has anti-inflammatory properties, which may protect against cholecystokinin-induced acute pancreatitis in rats. Cholecystokinin is known to exert trophic effects in several species. Taraxacum officinale has been used to cure liver and gallbladder disorders, which is attributable to its content of terpenoid and bitter sterol components such as taraxacin and taraxacerin[28], found that Taraxacum officinale induces apoptosis of human hepatoma (HepG2) cells through tumor necrosis factor $\alpha$ (TNF- $\alpha$ ) and interleukin (IL) $1 \alpha$ secretion, implying antiinflammatory effects within the central nervous system.

\subsection{Antioxidant Activity}

Dandelion Flowers are potential antioxidant resources, exerting their effect by way of their rich content of phenolic components including flavonoids, coumaric acid, and ascorbic acid. Their leaf extracts are effective hydrogen donors, hydrogen peroxide scavengers, and reducing agents. Several studies have demonstrated the antioxidative effect of dandelion. [29], extracts from dandelion leaf and root are hydrogen donating, ROS formation-inhibiting, and radicalscavenging. In anotherrecent study of dandelion flower extracts, ethyl acetate fraction scavenged ROS by preventing DNA from ROS-induced damage. The prevention of oxidative stress was due to the presence of bioactive components including luteolin and luteolin7-0-glucoside. [30]

\section{Conclusion}

This review shows that various medicinal properties of Taraxacum officinale are commonly reported in the scientific literature. These properties comprise hepatoprotective, anticolitis, immunoprotective, antiviral, antifungal, antibacterial, antiarthritic, antidiabetic, antiobesity, antioxidant and anticancer effects. Hepatoprotective, antioxidant and anticancer activities are the most frequently reported medicinal properties of Taraxacum officinale in the scientific literature. This plant represents a promising source for the prevention and treatment of health conditions. The protective action of Taraxacum officinale against hepatotoxicity, oxidative stress and cancer cell proliferation is well 
reported in the scientific literature. Further research is needed for validating the medicinal properties previously described and in the future days the use of this plant as a promising health remedy.

\section{Compliance with ethical standards}

\section{Acknowledgments}

The authors express sincere thanks to the Principal Dr. S. J. Dighade, VYWS's Institute of Pharmacy and Research Badnera, Amravati. We are thankful for their valuable support and guidance.

\section{Disclosure of conflict of interest}

There is no conflict of interest between the authors.

\section{References}

[1] Wirngo FE, Lambert MN, Jeppesen PB. The physiological effects of Dandelion (Taraxacum officinale) in Type 2 Diabetes. The Review of Diabetic Studies. 2016; 13: 2-3.

[2] AJ Richards Eutriploid facultative agamospermy in Taraxacum, New Phytologist. (1970); 69(3): 761-774.

[3] Richards, A.J. Dandelions of Great Britain and Ireland (Handbooks for Field Identification) Botanical Society of the British Isles Publications. 1997.

[4] McGraw-Hill Dictionary of Scientific \& Technical Terms (6th ed.). The McGraw-Hill Companies. 2003.

[5] Leung AY, Foster S. Encyclopedia of Common Natural Ingredients Used in Food, Drugs, and Cosmetics. New York: John Wiley and Sons. 1996; 205-207.

[6] Williams CA, Goldstone F, Greenham J. Flavonoids, cinnamic acids and coumarins from the different tissues and medicinal preparations of Taraxacum officinale. Phytochemistry. 1996; 42: 121-127.

[7] TS Kristo, E Szoke, A Kery, PP Terdy, B Selmeczi, B Simandi. Production and characerisation of Taraxacum officinale extracts prepared by supercritical fluid and solvent extractions. ISHS Acta Horticulturae 597. International Conference on Medicinal and Aromatic Plants-Part 2. 2001.

[8] G Rudenskaya. Taraxalisin- a serine proteinase from Taraxacum officinale Webb. FEBS Lett. 1998; 437: 237-240.

[9] E Cordatos. Taraxacumofficinale. In: Murray M, Pizzorno J, eds. A Textbook of Natural Medicine. Seattle: Bastyr University Press. 1992.

[10] LE Savre. ProcAmer Pharm Assoc. 1876; 16: 5.

[11] R Hansel, M Kartarahardja, J Huang, Bohlmann F. Sesquiterpene lactone betaD glucopyranosideesowieeinneues EudesmanolidausTaraxacumofficinale. Phytochem. 1980; 19(3): 857-61.

[12] C Symes. Pharm Jour Trans. 1872; 10: 361.

[13] HW Rauwald, JT Huang. Taraxacoside, a type of acylatedgammabutyrolactone glycoside from Taraxacumofficinale. Phytochem. 1985; 24(7): 1557-1559.

[14] W Kisiel, B Barszcz. Further sesquiterpenoids and phenolics from Taraxacumofficinale. Fitoterapia. 2000; 71(3): 269-73.

[15] E Racz-Kotilla, G RaczGand, A Solomon. The action of Taraxacum officinale extracts on the body weight and diuresis of laboratory animals. Planta Med. 1974; 26(3): 212-7.

[16] I Trojanova, V Rada, L Kokoska, E Vlkova. The bifidogenic effect of Taraxacum officinale root. Fitoterapia. 2004; 75(7-8): 760-3.

[17] HM Kim, EH Lee, TY Shin, KN Lee, JS Lee. Taraxacum officinale restores inhibition of nitric oxide production by cadmium in mouse peritoneal macrophages. Immuno pharm Immunotoxicol. 1998; 20(2): 283-97.

[18] HM Kim, CH Oh, CK Chung. Activation of inducible nitric oxide synthase by Taraxacum officinale in mouse peritoneal macrophages. Gen Pharm. 1999; 32(6): 683-8. 
[19] Y Kashiwada, K Takanaka, H Tsukada, Y Miwa, T Taga, S Tanaka. Sesquiterpene glucosides from anti-leukotriene B4 release fraction ofTaraxacum officinale. J Asian Nat Prod Res. 2001; 3(3): 191-7.

[20] C Hu C, Kitts DD: Antioxidant, prooxidant, and cytotoxic activities of solventfractionated dandelion (Taraxacum officinale) flower extracts in vitro. J Agric Food Chem. 2003; 51(1): 301-310.

[21] Seo S, Koo H, An H, Kwon K, Lim B, Seo E et al. Taraxacum officinale protects against cholecystokinin-induced acute pancreatitisin rats. World J Gastroenterol. 2005; 11(4): 597-599.

[22] Mao B, Wang G. Micro RNAs involved with hepatocellular carcinoma (Review). Oncol Rep. 2015.

[23] Mingarro DM, Plaza A, Galán A, Vicente JA, Martínez MP, Acero N. The effect of five Taraxacum species on in vitro and in vivo antioxidant and antiproliferative activity. Food Funct. 2015; 6: 2787-2793.

[24] You Y, Yoo S, Yoon HG, Park J, Lee YH, Kim S et al. In vitro and in vivo hepatoprotective effects of the aqueous extract from Taraxacum officinale (dandelion) root against alcohol-induced oxidative stress. Food ChemToxicol. 2010; 48(6): 1632-1637

[25] Seo S, Koo H, An H, Kwon K, Lim B, Seo E et al. Taraxacum officinale protects against cholecystokinin induced acute pancreatitis in rats. World J Gastroenterol. 2005; 11(4): 597-599.

[26] Grundy SM, Brewer HB, Cleeman JI, Smith SC, Lenfant C. Definition of metabolic syndrome: Report of the National Heart, Lung, and Blood Institute/American Heart Association conference on scientific issues related to definition. Circulation. 2004; 109(3): 433-438.

[27] Mir MA, Sawhney SS, Jassal MM. In-vitro antidiabetic studies of various extracts of Taraxacum officinale. PharmaInnov. 2015; 4(1): 61-66.

[28] Seo S, Koo H, An H, Kwon K, Lim B, Seo E et al. Taraxacum officinale protects against cholecystokinin induced acute pancreatitis in rats. World J Gastroenterol 2005; 11(4): 597-599.

[29] Hagymasi K, Blazovics A, Feher J, Lugasi A, Kristo ST, Kery A. The in vitro effect of dandelions antioxidants on microsomal lipid peroxidation. Phytother Res. 2000; 14(1):43-44.

[30] Prajakta N. Dongare, 2D QSAR Studies of flavonoid analogues for vascular relaxant Activity in coronary heart disease. International journal of Pharmacy. 2017; 7(2): 42-49. 